Article

\title{
Digital Light Processing (DLP) 3D Printing of Atomoxetine Hydrochloride Tablets Using Photoreactive Suspensions
}

\author{
Mirjana Krkobabić ${ }^{1}$, Djordje Medarević ${ }^{1}$, Nikola Pešić ${ }^{1}$, Dragana Vasiljević ${ }^{1}$, Branka Ivković ${ }^{2}$ \\ and Svetlana Ibrić ${ }^{1, *}$ \\ 1 Department of Pharmaceutical Technology and Cosmetology, Faculty of Pharmacy, University of Belgrade, \\ Vojvode Stepe 450, 11221 Belgrade, Serbia; mirjana.krkobabic@pharmacy.bg.ac.rs (M.K.); \\ djordje.medarevic@pharmacy.bg.ac.rs (D.M.); nikola.pesic@pharmacy.bg.ac.rs (N.P.); \\ dragana.vasiljevic@pharmacy.bg.ac.rs (D.V.) \\ 2 Department of Pharmaceutical Chemistry, Faculty of Pharmacy, University of Belgrade, Vojvode Stepe 450, \\ 11221 Belgrade, Serbia; branka.ivkovic@pharmacy.bg.ac.rs \\ * Correspondence: svetlana.ibric@pharmacy.bg.ac.rs; Tel.: +381-11-3951-371
}

Received: 27 July 2020; Accepted: 27 August 2020; Published: 31 August 2020

check for updates

\begin{abstract}
Three-dimensional (3D) printing technologies are based on successive material printing layer-by-layer and are considered suitable for the production of dosage forms customized for a patient's needs. In this study, tablets of atomoxetine hydrochloride (ATH) have been successfully fabricated by a digital light processing (DLP) 3D printing technology. Initial materials were photoreactive suspensions, composed of poly(ethylene glycol) diacrylate 700 (PEGDA 700), poly(ethylene glycol) 400 (PEG 400), photoinitiator and suspended ATH. The amount of ATH was varied from 10.00 to $25.00 \%(w / w)$, and a range of doses from 12.21 to $40.07 \mathrm{mg}$ has been achieved, indicating the possibility of personalized therapy. The rheological characteristics of all photoreactive suspensions were appropriate for the printing process, while the amount of the suspended particles in the photoreactive suspensions had an impact on the 3D printing process, as well as on mechanical and biopharmaceutical characteristics of tablets. Only the formulation with the highest content of ATH had significantly different tensile strength compared to other formulations. All tablets showed sustained drug release during at least the $8 \mathrm{~h}$. ATH crystals were observed with polarized light microscopy of photoreactive suspensions and the cross-sections of the tablets, while no interactions between ATH and polymers were detected by FT-IR spectroscopy.
\end{abstract}

Keywords: three-dimensional (3D) printing; digital light processing (DLP); photopolymerization; photoreactive suspensions; personalized therapy; sustained release

\section{Introduction}

Oral solid dosage forms are manufactured in precisely defined strengths, which can provide therapeutic effects for most of the population. The splitting of a solid dosage form is often necessary for dose adjustment to specific patients, which can result in a variation of drug content and inappropriate therapy. Dosing requirements change in different physiological and metabolic functions, and in comorbidities, often manifested in elders and children [1].

Current pharmaceutical manufacturing is not suitable for personalized medicines, while application of the three-dimensional (3D) printing (an additive manufacturing technology) in pharmacies might enable the production of small customized batches of solid dosage forms for oral administration with different dose and release characteristics [2,3]. 
All types of 3D printing technologies are based on the successive printing of material in layers, where a desired form predefined by 3D modeling software is obtained at the end of the printing [4]. $3 \mathrm{D}$ printing technologies can facilitate the fabrication of different dosage forms containing multiple drugs [5-7], dosage forms with immediate drug release [8-10], and modified drug release profiles [11,12]. Technologies investigated so far for production of medicines, where different drug releases were achieved, were the most commonly based on material extrusion [13,14], photopolymerization [12,15,16], binder jetting [17] and selective laser sintering (SLS) [18,19]. The main differences between 3D printing processes are the nature of the material used and the characteristics of the obtained products [20].

Photopolymerization processes use liquid photocurable resins, which undergo chemical reactions upon irradiation with light and fabricate solid objects [21]. Two types of additive manufacturing using photopolymers are stereolithography (SLA) and digital light processing (DLP). SLA uses a laser beam to scan the surface of the photopolymer mixture, enabling the fabrication of components with high resolution and good surface quality, while DLP uses a projector to selectively expose and cure an entire cross-sectional slice of the photopolymerizable resin at each given time [22-24]. In the consecutive immersion of the platform into the resin tank, the uncured photoreactive mixture crosses over the former cured layer, and in that way, every following layer is polymerized again by light and adheres to the previous layer. The process is repeated until the complete tablets are obtained [25].

Easy availability of DLP printers has made this technology promising, primarily in personalized medicine. It is noteworthy that the DLP technology is capable of fabricating dental models [26], and different implants for drug delivery [27]. The main disadvantage of processes based on photopolymerization is the potential cytotoxicity, caused by the unreacted monomer and photoinitiator residues [28]. Compared to other technologies, in DLP printing high drug loading has not been achieved yet, because it is necessary to provide sufficient content of photopolymer (which automatically reduces the possibility of incorporating an increased amount of other components) to obtain uniform tablets.

The photopolymers used so far in investigations of solid pharmaceuticals forms are poly(ethylene glycol) diacrylate (PEGDA) [12,16] and poly(ethylene glycol) dimethacrylate [12]. PEGDA is a synthetic, hydrophilic, biocompatible, and non-immunogenic material that can polymerize in the presence of photoinitiator and light [29].

Photoreactive solutions were mainly used to obtain solid pharmaceutical forms by 3D printing based on polymerization $[11,12,16,30]$. In our previous work, photoreactive suspensions with a suspended excipient were used in DLP printing, where the differences in the characteristics of the obtained tablets were noticed, depending on the type of initial photoreactive mixture [16]. However, there were no attempts to incorporate suspended active substances in the photoreactive mixture. Suspensions prepared for photopolymerization based 3D printing must be sufficiently transparent to the light to allow an acceptable cure depth [31]. Matching of the refractive index of medium and suspended phase can enable the preparation of highly loaded suspensions due to the minimization of the Van der Waals attraction forces [32]. It is desirable for photoreactive suspensions to have a viscosity less than $3000 \mathrm{mPa} \cdot \mathrm{s}$ for proper flow during the printing, where the viscosity of the initial monomer is important for final viscosity of suspensions [31].

The aim of this study was 3D printing of photoreactive suspensions with different amounts of the solid phase, and characterization of the photoreactive suspensions and obtained tablets. Atomoxetine hydrochloride (ATH) was chosen as an active substance due to the wide range of doses used in therapy (500 micrograms/kg daily-100 mg or $1.4 \mathrm{mg} / \mathrm{kg}$ daily), and its administration mostly in the child population, making it an ideal candidate for the development of personalized dosage forms [33]. The effect of the composition of photoreactive suspensions on drug release rates and kinetics, mechanical properties of tablets, and interactions between drug and polymers were also analyzed. 


\section{Materials and Methods}

\subsection{Materials}

Different photoreactive suspensions were prepared from poly(ethylene glycol) diacrylate 700 (PEGDA 700, Sigma-Aldrich, Tokyo, Japan), poly(ethylene glycol) 400 (PEG 400, Fagron B.V., Rotterdam, The Netherlands), atomoxetine hydrochloride (ATH, kindly provided by Hemofarm AD, Vrsac, Serbia), and diphenyl (2,4,6-trimethylbenzoyl) phosphine oxide (DPPO, Sigma-Aldrich, Steinheim, Germany). All other chemicals and reagents used in the study were of analytical grade.

\subsection{Methods}

\subsubsection{Preparation of Photoreactive Suspensions}

ATH was used as an active substance whose content varied from $10.00 \%$ to $25.00 \%$ ( $w / w$ ), while PEGDA was used as a photopolymer and DPPO as a photoinitiator. In photoreactive suspensions, PEG 400 was used as an excipient to overcome very slow and incomplete drug release from tablets fabricated by technologies based on photopolymerization. The ratio of PEGDA and PEG 400 was constant in all formulations (3:1) (Table 1).

Table 1. Different photoreactive suspensions for 3D printing.

\begin{tabular}{|c|c|c|c|c|}
\hline Formulation $\quad$ Substance & $\begin{array}{c}\text { ATH } \\
(\% w / w)\end{array}$ & $\begin{array}{l}\text { PEGDA } \\
(\% w / w)\end{array}$ & $\begin{array}{l}\text { PEG 400 } \\
(\% w / w)\end{array}$ & $\begin{array}{c}\text { DPPO } \\
(\% w / w)\end{array}$ \\
\hline A1 & 10.00 & 66.75 & 22.25 & 1.00 \\
\hline A2 & 15.00 & 63.00 & 21.00 & 1.00 \\
\hline A3 & 20.00 & 59.25 & 19.75 & 1.00 \\
\hline A4 & 25.00 & 55.50 & 18.50 & 1.00 \\
\hline
\end{tabular}

PEG 400 was chosen due to previous experience, where it was used in the production of uniform tablets, and PEGDA/PEG 400 ratio 3:1 was used for the production of the tablets with appropriate tensile strength and dissolution rate [16]. It was prepared $50 \mathrm{~g}$ of each photoreactive suspension by mixing on the magnetic stirrer for $12 \mathrm{~h}$. During the preparation and the printing process, all formulations were protected from the light.

\subsubsection{Determination of Drug Content in Photopolymer Suspensions}

The drug content in photopolymer suspensions of each formulation was determined in triplicate. Photopolymer suspensions (quantity equivalent to $10 \mathrm{mg}$ of active substance) were placed in a volumetric flask with distilled water $(100 \mathrm{~mL})$ and shaken on the ultrasound bath for $15 \mathrm{~min}$. The samples then were filtered through $0.45 \mu \mathrm{m}$ filters (Millipore, Bedford, MA, USA), and drug loading was determined by UV/VIS spectrophotometry (Evolution 300, Thermo Fisher Scientific, Waltham, MA, USA) at $270 \mathrm{~nm}$.

\subsubsection{Determination of Drug Content in Tablets}

Three separate tablets were crushed per batch and $10 \mathrm{mg}$ equivalents taken from the one tablet each, dissolved in $100 \mathrm{~mL}$ of distilled water and shaken inside the ultrasound bath for $15 \mathrm{~min}$. The samples then underwent the same procedure as described for samples prepared from photopolymer suspensions (Section 2.2.2). The results were expressed as an average ATH \pm standard deviation (S.D.) [34].

\subsubsection{Refractive Index of the Suspension Measurements}

The refractive index $n$ of all photoreactive suspensions was determined using a refractometer (ABBE bench refractometer, 2WAJ, OPTIKA microscopes, Ponteranica, Italy). The refractometer was set up to measure the refractive index in the wavelength corresponding to the D-line of sodium (589.3 $\mathrm{nm}$ ). An average of three measurements was taken for all photoreactive suspensions. 


\subsubsection{Rheological Measurements}

The rheological measurements of the suspensions were carried out on a Rheolab MC 120 (Paar Physica, Stuttgart, Germany) rheometer coupled with the rotating cylinder measuring device Z3 DIN (diameter $25 \mathrm{~mm}$ ) at $20 \pm 0.1^{\circ} \mathrm{C}$. The controlled shear rate (CSR) procedure was applied to the flow curve construction, by increasing the shear rate from 0 to $2001 / \mathrm{s}$. The rheological characterization of the photoreactive suspensions was performed to relate the properties of the photopolymer mixtures via the $3 \mathrm{D}$ printing process and the characteristics of the obtained tablets. The measurements were performed in triplicate for each sample.

\subsubsection{D Printing of ATH Tablets}

The cylindrical shape of the tablets was designed by Autodesk Fusion 360 software (Autodesk Inc., San Rafael, CA, USA) and exported as a stereolithography file (.stl) into Creation Workshop X 1.2.1 software. The DLP printer Duplicator 7 (Wanhao, Zhejiang, China) (Figure 1) was used for the fabrication of tablets for all formulations. The dimensions of tablets were $8 \mathrm{~mm}$ in diameter and $2 \mathrm{~mm}$ in height.

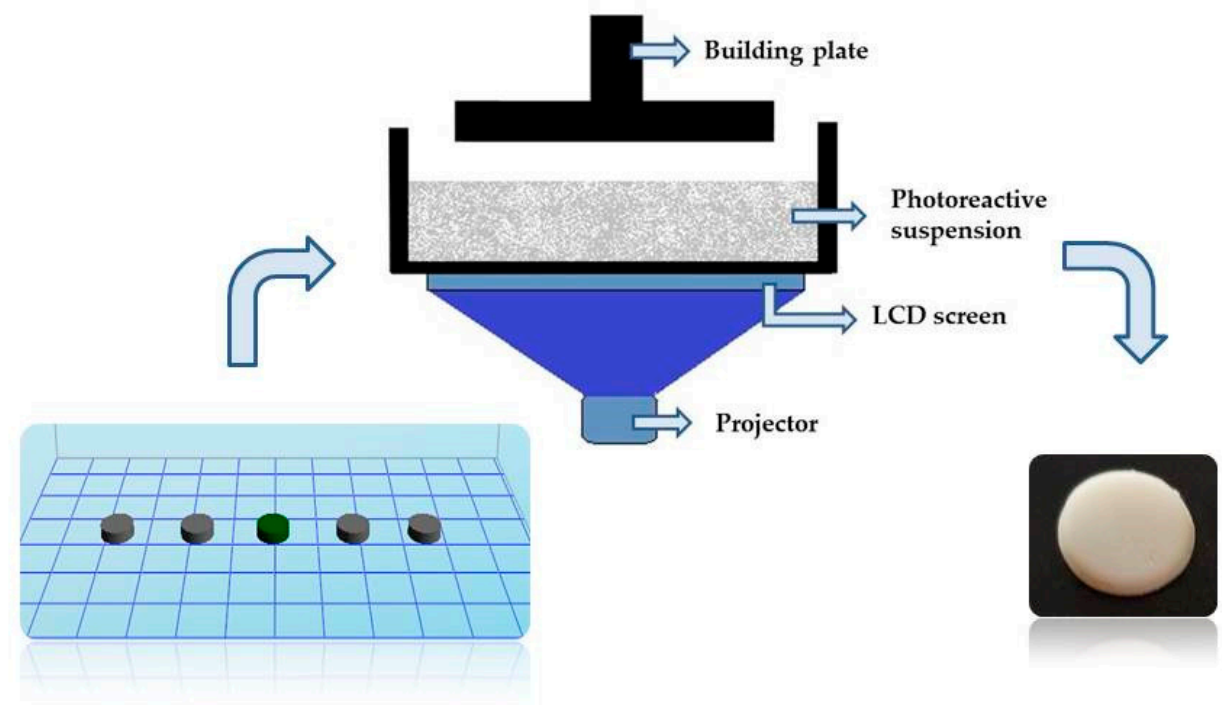

Figure 1. Illustration of the 3D DLP printing.

For formulations A1-A4, it was examined which printing parameters allow the adhesion of the tablets to the building plate and do not lead to over curing of the photoreactive suspension. Previous studies $[15,35]$ have shown that it is necessary to adjust the printing parameters for each formulation separately, because there are no predefined optimal conditions as is the case with commercially available photoreactive mixtures used in other industries. Photopolymerization was conducted for layers thickness of $0.1 \mathrm{~mm}$, to prevent problems with light penetration which can occur due to the interaction of light with suspended particles. All tablets were fabricated including 5 bottom layers, with different bottom layer exposure for different formulations, depending on the proportion of ATH in photoreactive suspensions. For tablets containing $10.00 \%$ and $15.00 \%$ of ATH, the bottom layer exposure was set at $30 \mathrm{~s}$, while for tablets containing $20.00 \%$ and $25.00 \%$ of ATH was set at $70 \mathrm{~s}$. Higher bottom layer exposure was required for tablets with a higher proportion of active substance to adhere to the building plate. The exposure time of the remaining layers was $15 \mathrm{~s}$ per layer for each formulation, and the total number of layers, following the specified dimensions, was 20 . The printing time depended on the total exposure time and lasted from $10 \mathrm{~min} 30 \mathrm{~s}$ to $13 \mathrm{~min} 15 \mathrm{~s}$ for 5 tablets. 


\subsubsection{Determination of Mass, Dimension and Tensile Strength of Tablets}

Mass was determined on 20 tablets, while dimensions (digital caliper, Vogel Germany GmbH \& Co. KG, Kevelaer, Germany) were measured on 10 tablets for each formulation. Hardness was estimated on 10 tablets per formulation using a hardness tester (TBH 125D, Erweka, Langen, Germany), and tensile strength was calculated according to the following equation [36]:

$$
\sigma_{\mathrm{x}}=2 \mathrm{~F} / \pi \mathrm{Dt}
$$

In the previous equation, $\sigma_{\mathrm{x}}$ is the tensile strength, $\mathrm{F}$ is the tablet breaking force, $\mathrm{D}$ is the diameter, and $t$ is the thickness of tablets.

Statistical analysis was performed using PASW Statistics 18.0 (SPSS Inc., Chicago, IL, USA), and a comparison of all raw data involved a normality and homogeneity test. A parametric one-way ANOVA was used when homogeneity and normality were found, with significance levels $p<0.05$. Post hoc Tukey's test was applied due to the same number of data in every group to determine between which formulations there was significant difference.

\subsubsection{Polarized Light Microscopy}

The Olympus BX51-P polarizing microscope (Olympus, Tokyo, Japan) with cellSens Entry software was used for visual analysis of ATH powder, photoreactive suspensions and prepared tablets. The particle size of the pure ATH and of the particles in photoreactive suspensions was estimated using the ImageJ software (National Institutes of Health, Bethesda, MD, USA). The photoreactive suspensions were diluted with n-hexane (1:1) to make the ATH particles more visible. Measurements of length were made per one hundred randomly selected particles in diluted photoreactive suspensions, as well as for ATH powder, and the results were shown as mean ( \pm S.D.), minimum, and maximum length.

Polarized light microscopy was used for observation of a cross-section of tablets to compare the internal structure of the tablets with the photoreactive suspensions from which they were obtained and also for the detection of the crystalline components.

\subsubsection{Fourier Transform Infrared Spectroscopy (FT-IR)}

Nicolet iS10 (Thermo Scientific, Waltham, MA, USA) FT-IR spectrometer, equipped with a single reflection ATR system (Smart iTR, Thermo Scientific, Waltham, MA, USA) with diamond plate and $\mathrm{ZnSe}$ lens, was used to record FT-IR spectra of raw materials and crushed tablets. The wavenumbers were from 650 to $4000 \mathrm{~cm}^{-1}$, with a resolution 4, while the spectra were collected as an average of 16 scans. The analysis was performed to identify potential interactions between the components in the tablets.

\subsubsection{In Vitro Drug Release Testing}

Initial experiments performed on 3D printed ATH tablets in our laboratory showed that the choice of apparatus (paddle apparatus or flow-through cell) and medium (distilled water or $0.1 \mathrm{M} \mathrm{HCl}$ ) had no significant effect on the dissolution rate of ATH from tablets. ATH dissolution rate from 3D printed tablets was tested using USP IV (Flow-through cell, CE7 smart, Sotax, Aesch, Switzerland) apparatus. Three tablets of each formulation were tested in $250 \mathrm{~mL}$ of distilled water at $37 \pm 0.5^{\circ} \mathrm{C}$, with a flow rate of $8 \mathrm{~mL}$ per minute, during $8 \mathrm{~h}$. The samples $(4 \mathrm{~mL})$ were withdrawn at 15, 30, 45, 60, 120, 180, $240,300,360,420$, and 480 min time intervals and immediately replaced with a fresh medium, while samples were filtered through $0.45 \mu \mathrm{m}$ membrane filters (Millipore, Bedford, MA, USA). The amount of dissolved ATH was determined by UV/VIS spectrophotometry at $270 \mathrm{~nm}$ (Evolution 300, Thermo Fisher Scientific, Waltham, MA, USA). 


\subsubsection{Kinetic Modeling of Drug Release}

The mechanism of ATH release from the tablets was analyzed by fitting the data of an eight-hour in vitro dissolution test of each formulation into zero-order, first-order, Higuchi, and Korsmeyer-Peppas models [37,38]. Fitting the data into these mathematical models was performed by using the DDSolver software (Microsoft Excel add-in program) developed by Zhang et al. [38]. Mathematical models applied to the obtained data are shown in Table 2.

Table 2. Equations of mathematical models commonly used to describe mechanisms of drug release, where $\mathrm{Mt} / \mathrm{M} \infty$ is the fraction (\%) of drug released after time $t, K_{0}, K_{1}, K_{H}, K_{P}$ are drug release rate constants for the corresponding models and $\mathrm{n}$ is release exponent, indicating the mechanism of transport of drug.

\begin{tabular}{cc}
\hline Mathematical Models & Equations \\
\hline Zero-order & $\mathrm{M}_{\mathrm{t}} / \mathrm{M}_{\infty}=\mathrm{K}_{0} \cdot \mathrm{t}$ \\
First-order & $\mathrm{M}_{\mathrm{t}} / \mathrm{M}_{\infty}=100\left[1-\mathrm{Exp}\left(-\mathrm{K}_{1} \cdot \mathrm{t}\right)\right]$ \\
Higuchi model & $\mathrm{M}_{\mathrm{t}} / \mathrm{M}_{\infty}=\mathrm{K}_{\mathrm{H}} \cdot \mathrm{t}^{1 / 2}$ \\
Korsmeyer-Peppas model & $\mathrm{Mt} / \mathrm{M}_{\infty}=\mathrm{K}_{\mathrm{p}} \cdot \mathrm{t}^{\mathrm{n}}$ \\
\hline
\end{tabular}

\section{Results and Discussion}

\subsection{Drug Content in Photopolymer Suspensions and Tablets}

The drug content in the different photoreactive suspensions indicates that suspensions were homogenous. The content of ATH in 3D printing tablets and the photoreactive suspensions were similar; only formulation A1, with the lowest content of ATH, had the complete recovery in photoreactive suspension, but all photoreactive suspensions had ATH content $95.58-100.29 \%$, which can be considered as acceptable; the lower content in tablets compared to the content in photoreactive suspensions may be due to the entrapped small fraction of the active substance in the tablet matrix, which is difficult to extract during the sample preparation. It has been previously shown that decrease of drug content in tablets compared to initial mixture could be due to retention of an active substance in the drug-polymer matrix [11]. In all tablets, the content of ATH was $95.35-96.46 \%$ of the theoretical content, which indicates that homogeneity in tablets was achieved, and there was no unaccepted degradation of the active ingredient during photopolymerization in the 3D printing process (Table 3 ).

Table 3. Drug content in photopolymer suspensions and tablets ( $\% \pm$ S.D.).

\begin{tabular}{ccc}
\hline Formulation & Drug Content in Photoreactive Suspensions & Drug Content in Tablets \\
\hline A1 & $100.29 \pm 0.87$ & $96.46 \pm 3.88$ \\
A2 & $95.66 \pm 1.88$ & $95.62 \pm 2.93$ \\
A3 & $96.78 \pm 0.90$ & $96.12 \pm 1.80$ \\
A4 & $95.58 \pm 1.07$ & $95.35 \pm 0.70$ \\
\hline
\end{tabular}

\subsection{Refractive Index of The Suspensions Measurements}

Measured values of the refractive index are shown in Table 4. All formulations with the ATH had a higher refractive index compared to the placebo formulation (PEGDA + PEG $400+$ photoinitiator).

Table 4. Refractive index of the placebo and the ATH formulations (mean value \pm S.D.).

\begin{tabular}{cc}
\hline Formulation & Refractive Index \\
\hline PEGDA+PEG 400 + photoinitiator & $1.4572 \pm 0.0000$ \\
A1 & $1.4661 \pm 0.0001$ \\
A2 & $1.4675 \pm 0.0004$ \\
A3 & $1.4685 \pm 0.0004$ \\
A4 & $1.4690 \pm 0.0001$ \\
\hline
\end{tabular}


The changed refractive index of photoreactive suspensions compared to the placebo formulation had the potential impact on the printing process, and tablets characteristics. The refractive index of ATH is 1.552 [39], indicating a large difference between the solid phase and placebo refractive indices, which could lead to inaccuracies in printing and differences in dimensions [40], and consequently on the mass of the tablets.

\subsection{Rheological Characterization of Photoreactive Suspensions}

Flow and viscosity curves of investigated samples are given in Figures 2 and 3, respectively. Placebo and four photoreactive suspensions with ATH exhibited dilatant flow behavior at lower shear rates (below approximately $30 \mathrm{1} / \mathrm{s}$ ), followed by Newtonian flow at higher shear rates. In dilatant (i.e., shear thickening) flow behavior, the viscosity increases with the increasing shear rate, while a Newtonian fluid's viscosity remains constant i.e., viscosity is independent of shear rate [41]. The type of flow was the same for placebo and formulations with ATH, so it was most affected by polymers, in the first place by PEGDA.

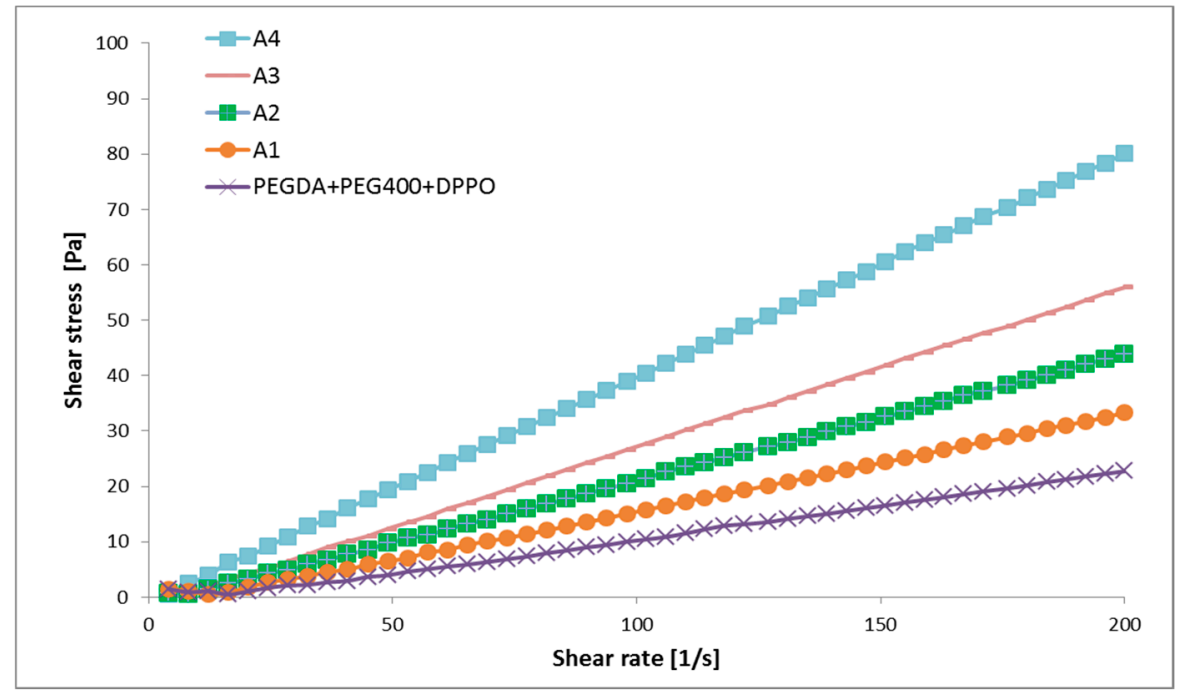

Figure 2. Flow curves of the placebo and the ATH suspensions.

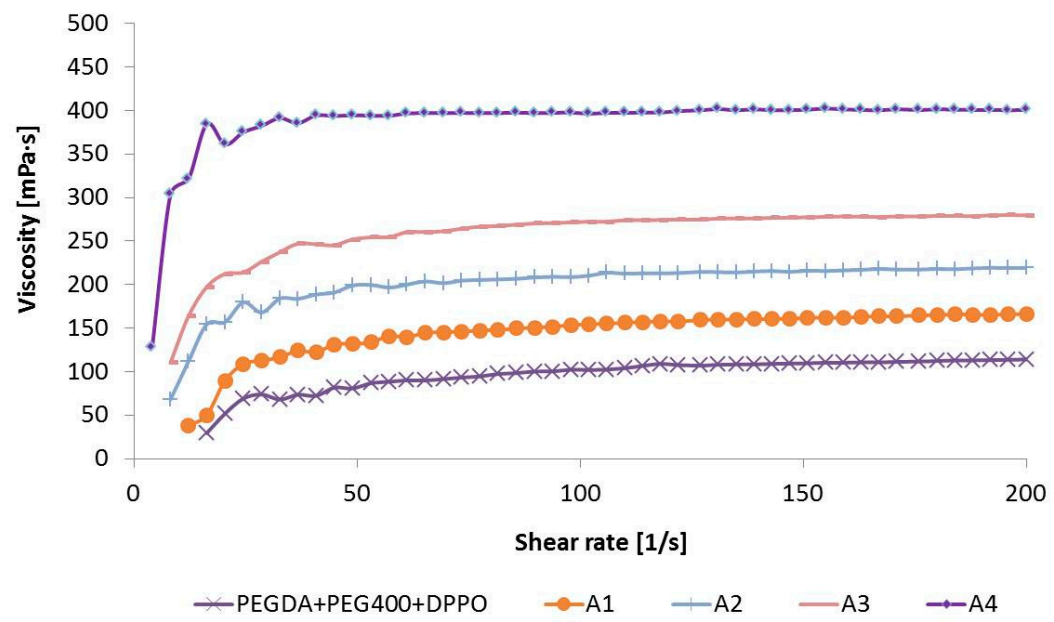

Figure 3. Viscosity curves of the placebo and ATH suspensions.

It is known that the viscosity of suspensions depends on a number of factors, including the volume fraction of the solid phase, the type of suspended particles, and their shape, size and size 
distribution [42]. In this case, the viscosity of the suspensions increased significantly with the increase in the proportion of ATH. The suspension with the highest proportion of ATH $(25.00 \%)$ had the highest value of viscosity (approximately $400 \mathrm{mPa} \cdot \mathrm{s}$, at 30-200 1/s), while placebo formulation the lowest viscosity values (approximately $100 \mathrm{mPa} \cdot \mathrm{s}$, at 30-200 1/s) (Figure 3).

All photoreactive suspensions had a viscosity notably bellow $3000 \mathrm{mPa} \cdot \mathrm{s}$ (Figure 3), which was important for successful printing [31]. The viscosity of the suspensions affected the printing time, mass, dimensions and tensile strength of the tablets. The high viscosity could hinder precise layer thickness and increase curing time [43].

\subsection{Polarized Light Microscopy of the ATH Powder and Photoreactive Suspensions}

Particles of pure ATH, mean diameter, the minimal and maximal size of particles, were analyzed on magnification $10 \times$ (Figure 4). It is important to emphasize that manually selecting only 100 particles gives a low-quality estimate of the real particle size distribution, but microscopic analysis provides insight into the shape of the particles. The mean particle size was $26.97 \pm 12.13 \mu \mathrm{m}$, while the minimal and maximal size of particles in the sample was 8.70 and $76.67 \mu \mathrm{m}$, respectively, which indicates that there was a wide particle size distribution in the initial powder, and the same could be expected for prepared suspensions.

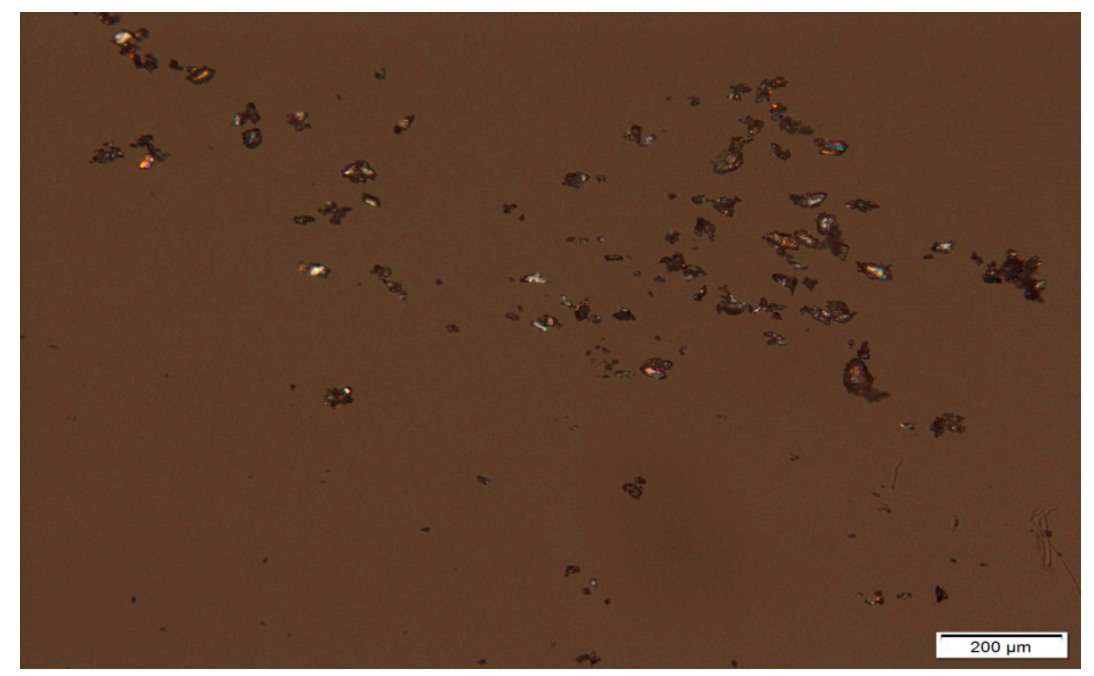

Figure 4. Micrograph of ATH powder sample at 10× magnification.

Photoreactive suspensions of ATH were diluted with n-hexane (1:1), to allow better observation of particles that were not dissolved in the polymer mixture. A 10× magnification was used for the observation of the shape and size of particles in photoreactive suspensions. From these micrographs, it can be seen that birefringence occurred; crystals were presented in the samples, and their shapes were irregular (Figure 5). Mean diameter, minimal and maximal size of particles are shown in Table 5.

The particle size distribution was wide, but regardless of that, the production of tablets was possible. It would be necessary to uniform the particle size distribution of the solid phase before the preparation of photoreactive suspensions to obtain results with less variation in mass and dose.

The solubility of ATH over a biologically relevant $\mathrm{pH}$ range is all well above the maximum dose strength $(100 \mathrm{mg}) / 250 \mathrm{~mL}$, demonstrating the high solubility of ATH. Its solubility is $27.8 \mathrm{mg} / \mathrm{mL}$ in water [44], but ATH has a very bitter taste [45], which can be overcome by preparing the suspension of ATH in PEGDA photopolymer mixture, while the instability of the suspensions can be overcome by using them for tablet preparation, as the final pharmaceutical dosage form [46].

Ideal suspension formulations should contain insoluble particles uniformly suspended in the continuous phase, but during the standing, the solid particles in suspensions get separated from 
the liquid as sediments. Despite the amount of sedimentation, suspensions should be redispersed uniformly after careful shaking. It is known that the disadvantage of suspension dosage forms includes the possibility of dose variation. The most important parameter connected to the sedimentation is the particle size, where smaller particles yield a low rate of sedimentation. A narrow particle size distribution is desirable for uniform sedimentation rate and then is possible to provide better predictability of suspension properties. Increasing viscosity of the medium can decrease the rate of sedimentation, while the redispersion can be controlled by using flocculating agents. All the mentioned factors affect the stability of suspensions [46]. Photoreactive suspensions differ from suspensions intended for direct application; they represent an initial mixture for 3D printing, however, the same factors should be considered for them. The photoreactive suspensions of ATH were stable enough for the printing process because they were immediately placed in the printer after mixing, where printing took a short time, which is one of the benefits of this type of 3D printing. However, further testing would be needed for a potential production in pharmacies, as the wide particle size distribution and irregular particle shape shown in the micrographs could cause suspension instability and further problems in the printing process.
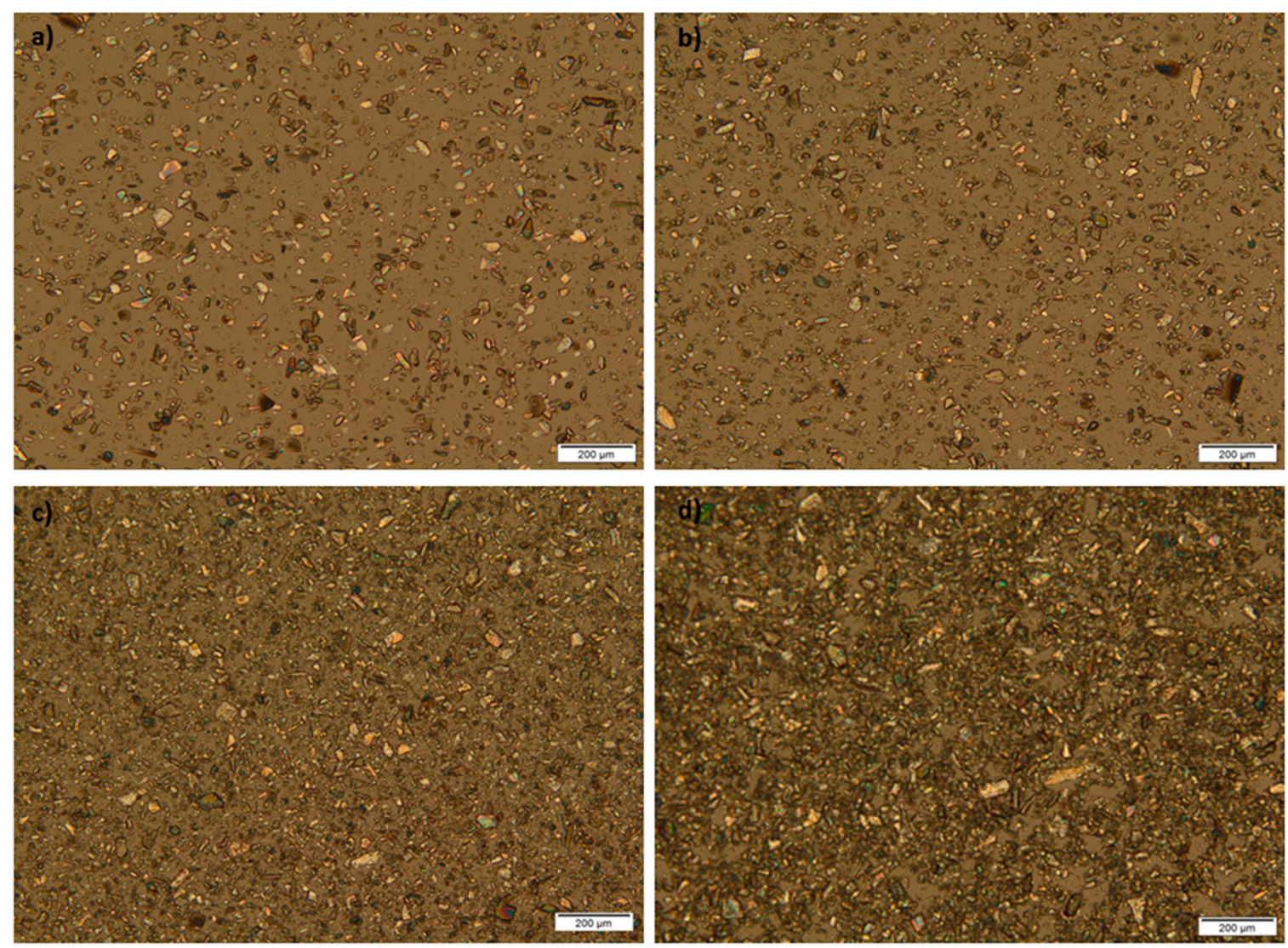

Figure 5. Micrographs of photoreactive suspensions at 10x magnification: (a) A1; (b) A2; (c) A3; (d) A4 formulation.

Table 5. Mean diameter \pm S.D., minimal and maximal size of ATH particles in photoreactive suspensions.

\begin{tabular}{cccc}
\hline Formulation & Mean \pm S.D. $(\mu \mathrm{m})$ & Min $(\mu \mathrm{m})$ & Max $(\mu \mathrm{m})$ \\
\hline A1 & $22.60 \pm 12.57$ & 4.36 & 63.65 \\
A2 & $21.53 \pm 10.14$ & 5.29 & 58.50 \\
A3 & $29.61 \pm 12.51$ & 8.61 & 71.84 \\
A4 & $34.68 \pm 13.27$ & 13.61 & 72.93 \\
\hline
\end{tabular}




\subsection{D Printing Process}

So far, PEGDA 575, without the addition of any excipients or with addition of PEG 300, was used for printing polypills containing: paracetamol, naproxen, caffeine, aspirin, prednisolone, and chloramphenicol [15], while PEGDA 400 was used for printing tablets containing theophylline as active substance. Paracetamol [11,16], 4-aminosalicylic acid [11] and ibuprofen [35,47], were used as active substances in photopolymerization based printing processes, combined with a mixture of PEGDA and PEGs of different molecular weights. In our study, tablets containing four different amounts of ATH suspended in PEGDA/PEG 400 mixture were successfully produced by the DLP printer. In the work by Xu et al. (2020), PEGDA 575 and PEG 300 were used for production of the antihypertensive polyprintlet (irbesartan, atenolol, hydrochlorothiazide and amlodipine), where chemical reaction between a photopolymer and amlodipine reported [48]. Accordingly, different active substances could be dissolved or suspended in the PEGDA/PEGs mixtures, but it is important to investigate potential interactions between drugs and polymers.

To provide quality and safety of obtained tablets, 3D printing processes for pharmaceutical use need to be complementary with Good Manufacturing Practice (GMP) pharmaceutical standards. In accordance with the described procedure of preparation of the photoreactive suspensions and printing of tablets with DLP 3D technology, this process, as well as other 3D printing technologies, could take a role in preparations of personalized dosage forms in community and hospital pharmacies [49]. The benefits of using the DLP printer here demonstrated are the possibility of customization of the printing parameters depending on the formulation factors, fast printing of pharmaceutical dosage forms, as well as printing at room temperature. Previous studies based on DLP 3D printing have also shown these possibilities as potential advantages of this technology $[12,16,35]$. In comparison with other 3D printing technologies investigated for tablet production, DLP has a limited number of photopolymers suitable for pharmaceutical use.

\subsection{Appearance, Mass, Doses, and Dimension of the Tablets}

Tablets of all formulations were white and showed the same color as the initial photoreactive suspensions. Mass, dose, diameter, and thickness of the tablets are shown in Table 6.

Table 6. Mass, dose and dimensions of the tablets (mean \pm S.D.).

\begin{tabular}{|c|c|c|c|c|}
\hline Parameter & $\begin{array}{l}\text { Mass } \pm \text { S.D. } \\
(\mathrm{mg})\end{array}$ & $\begin{array}{l}\text { Dose } \pm \text { S.D. } \\
(\mathrm{mg})\end{array}$ & $\begin{array}{c}\text { Diameter } \pm \text { S.D. } \\
(\mathrm{mm})\end{array}$ & $\begin{array}{c}\text { Thickness } \pm \text { S.D. } \\
(\mathrm{mm})\end{array}$ \\
\hline A1 & $122.08 \pm 11.69$ & $12.21 \pm 1.70$ & $7.70 \pm 0.17$ & $1.94 \pm 0.17$ \\
\hline A2 & $130.18 \pm 10.00$ & $19.53 \pm 1.50$ & $7.84 \pm 0.18$ & $2.03 \pm 0.13$ \\
\hline A3 & $159.81 \pm 11.35$ & $31.96 \pm 2.27$ & $8.06 \pm 0.30$ & $2.07 \pm 0.23$ \\
\hline A4 & $160.29 \pm 4.71$ & $40.07 \pm 1.18$ & $8.35 \pm 0.13$ & $2.16 \pm 0.08$ \\
\hline
\end{tabular}

The increase in the ATH content led to the fabrication of tablets with a higher mass and dimensions, due to the higher viscosity, and the higher proportion of ATH particles suspended and their scattering phenomena in the light beam. With increasing content of particles in the suspensions, the intensity of light scattering increases and affects the dimensions and consequently the mass of the tablets; when the particle size is not constant (as in the case of A1-A4 formulations), it is not possible to establish a linear relationship between particle concentration and light scattering [50]. It has been shown by Mitteramskogler and Gerald (2014) that the light scattering in ceramic suspensions caused a certain amount of widening of the dimensions in the final geometry, where exposure time and exposure area also had influence [51]. Printing from photoactive solutions did not cause problems with the dimensions and the shape of the tablets, as shown in the works of Kadry et al. (2019) and Martinez et al. (2018) [12,30], while photoreactive suspensions can cause over curing during the printing tablets of different shapes and sizes [16], which was avoided in this research by production tablets of smaller dimensions (8 $\mathrm{mm}$ in diameter). According to "Guideline on pharmaceutical development of medicines 
for pediatric use", tablets smaller than $10 \mathrm{~mm}$ are suitable for use in children aged above 6 years [52], which indicates that ATH 3D printed tablets could be used in the target population because ATH is used in the treatment of attention deficit hyperactivity disorder in adults and children aged 6 years and over [33].

Formulation A3 had the smallest variation from the previously set diameter, while formulation A2 varied the least from the thickness specified in the Creation Workshop software. Formulation A1 had a diameter and a thickness less than the specified, while formulation A2 had only a diameter lower than the specified $8 \mathrm{~mm}$. Formulations A3 and A4 had dimensions larger than previously set. ATH tablets had smaller deviations from the given dimensions compared to the tablets containing suspended mannitol in the previous study. However, tablets containing mannitol had longer exposure time conditions and over curing was a possibility that could occur, which was not the case with ATH tablets [16].

The achieved dose was from 12.21 to $40.07 \mathrm{mg}$, which can allow personalization of the therapy. The standard deviation that occurred in the variation of the tablet's mass and thus the achieved dose could be reduced by using a higher resolution 3D printer and a uniform particle size in the suspension.

\subsection{Tensile Strength of the Tablets}

The ratio of PEGDA and PEG 400 was the same in all formulations, so the content of ATH and amount of photoinitiator relative to PEGDA: PEG 400 influenced the tensile strength of the tablets. Increasing content of active ingredient led to the higher tensile strength of tablets, and all formulations had tensile strength around $1 \mathrm{MPa}$. Although $1 \mathrm{MPa}$ is appropriate for the production of small batches [53], due to the operating with the photoreactive suspensions and the printer, the achieved tensile strengths may be sufficient for use in individual patients in pharmacies.

Only formulation A4 shows a statistically significant difference compared to other formulations. It was possible to print tablets with $10.00 \%, 15.00 \%$, and $20.00 \%$ of ATH without significantly affecting the mechanical properties of the tablets (Figure 6). Increasing tensile strength of tablets with increasing the proportion of ATH can also be the result of different bottom layer exposures, where longer bottom layer exposure can lead to better adhesion of the layers.

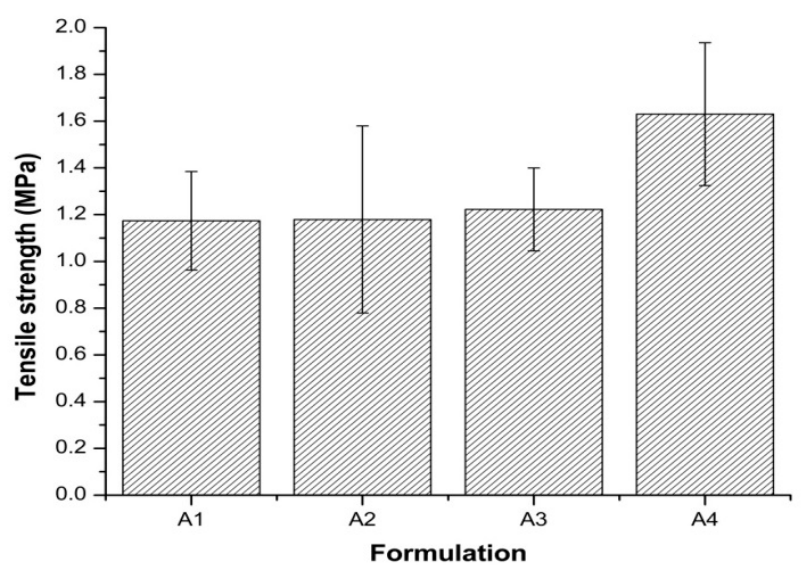

Figure 6. Tensile strength of all formulations.

High variations of tablet tensile strength were observed in all formulations which may be due non-uniform photopolymerization in all directions of the tablet layers, which can be caused by the wide range of particle size distribution. 


\subsection{Polarized Light Microscopy of the Tablets Cross-Section}

In all cross-sectional views of 3D printed tablets containing 10.00-25.00\% of suspended ATH, visible parallel layers cannot be observed. It can be seen on micrographs that birefringence occurs and that in tablets, as well as in photoreactive suspensions, crystals were presented (Figure 7). In this way, it has been shown that ATH remained in crystalline state in tablets. It is important to emphasize that homogenous distribution of ATH in the tablets was observed, without agglomerates. Nonhomogeneous distribution of drugs, with agglomeration of drug particles can cause unacceptable variations in drug release within the same batch of extended release matrix tablets. Darker structures on the micrographs most likely appeared due to thicker parts of the tablets cross-section, which disabled light penetration and could be seen during the analysis.
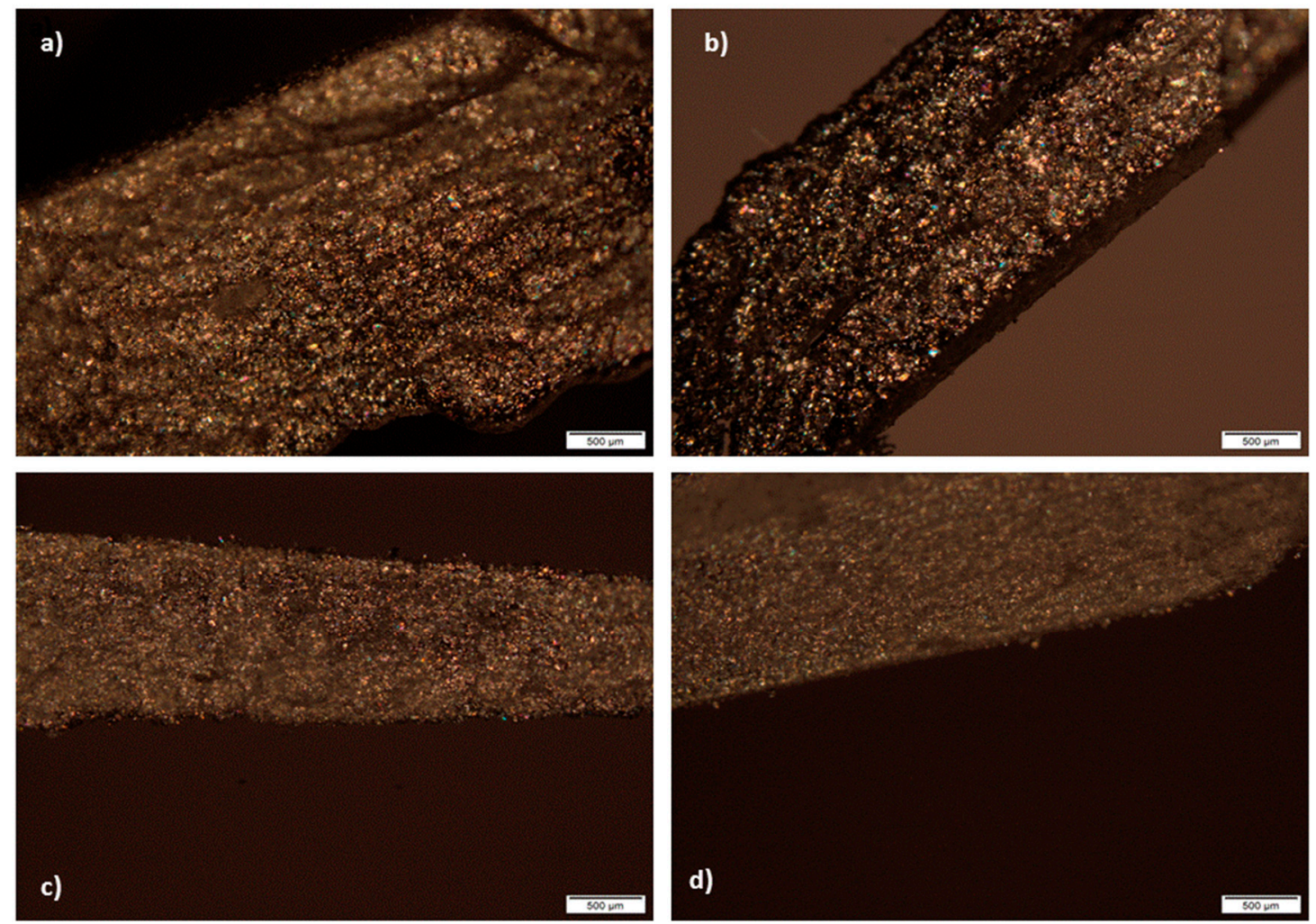

Figure 7. Cross-sectional views of tablets: (a) A1; (b) A2; (c) A3; (d) A4 formulations.

As shown in a previous study, it was possible to see the layers on the cross-section of the tablets obtained from the photoreactive solutions in DLP printing using polarized light microscopy, while the presence of suspended ingredients prevents observation of parallel layers [16]. This indicates that in the case of ATH tablets, the layers were not visible due to the ATH crystals that covered them.

\subsection{Fourier Transform Infrared Spectroscopy (FT-IR)}

FT-IR spectroscopy was used for the detection of interactions between ATH and polymers used for the preparation of tablets.

Liquid uncured PEGDA contained characteristic acrylate peaks at $\sim 1636 \mathrm{~cm}^{-1}$ and $\sim 1618 \mathrm{~cm}^{-1}$ ( $C=C$ stretching) [54], which was difficult to identify in A1-A4 formulations after photopolymerization, due to conversion of $\mathrm{C}=\mathrm{C}$ to $\mathrm{C}-\mathrm{C}$ bonds $[16,55]$. The PEGDA showed characteristic $\mathrm{C}=\mathrm{O}$ symmetric stretching absorption band at $1731 \mathrm{~cm}^{-1}$ in all ATH formulations [56], while peaks characteristic for the PEG 400 were at $\sim 1096 \mathrm{~cm}^{-1}$ (C-O-C ether stretching) and at $\sim 2867 \mathrm{~cm}^{-1}$ corresponding to $-\mathrm{C}-\mathrm{H}$ symmetric and asymmetric stretching vibrations [57]. Prominent peaks from ATH observed in tablets were at $\sim 1242$ and $\sim 1009 \mathrm{~cm}^{-1}$ indicating ArO-R stretching and R-NH stretching [58]. It has been shown 
that there was a negligible difference in the position of the peaks and there were no drug-polymer interactions (Figure 8).

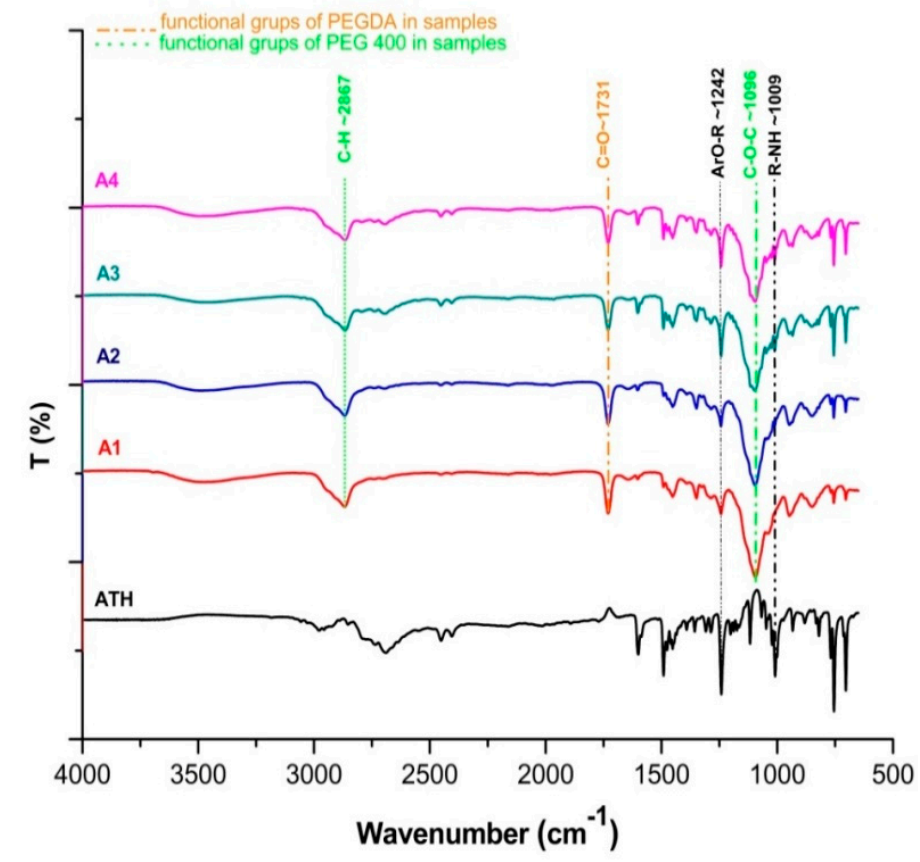

Figure 8. FT-IR spectra of pure ATH and A1-A4 formulations.

\subsection{In Vitro ATH Release}

Dissolution profiles of formulations containing different amounts of ATH are shown in Figure 9. After $8 \mathrm{~h}, 66.75 \%$ and $69.62 \%$ of ATH was released from formulations A1 and A2, while $76.96 \%$ and $87.60 \%$ of ATH was released from formulations A3 and A4, respectively. As previously shown, PEGDA polymer has been confirmed to be suitable for the production of sustained release tablets $[11,16,30]$.

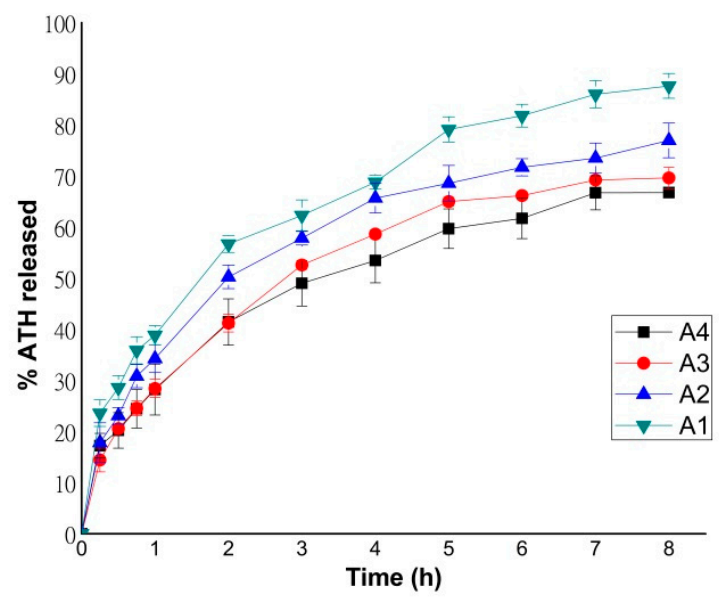

Figure 9. Dissolution profiles of formulations A1-A4.

The content of ATH in formulations influenced the dissolution rate; with the increasing of the ATH content, the percentage of the released substance also increased during $8 \mathrm{~h}$. Formulation A4 had the lowest content of PEGDA, and this is a potential reason why this formulation had the fastest drug release. As shown in previous studies, a lower amount of PEGDA probably increased the drug release rate due to a lower degree of cross-linking in the tablet matrix [11,16]. 
During dissolution, the ATH tablets did not suffer erosion from the surface or disintegration into smaller fractions, but swelling occurs and the tablets remained intact at the bottom of the cell, which was demonstrated in previous studies where PEGDA was used as a photopolymer [12,15,54]. Tablets printed from higher viscosity suspensions showed a higher dissolution rate after $8 \mathrm{~h}$.

\subsection{ATH Release Kinetics}

Model dependent analysis of the obtained ATH release profiles was used to elucidate the impact of increasing content of the suspended active substance on the drug release. It has been previously shown that the mechanism of drug release from formulations with PEGDA and PEG 400 is most consistent with the Korsmeyer-Peppas model, as well as for formulations where mannitol and sodium-chloride solution were used as excipients [16]. In the previous study [35] where, in addition to PEGDA and PEG 400, water was used as an additional excipient, most formulations showed Higuchi kinetics, while some formulations also showed zero-order kinetics. In the study by Cerda et al. (2020), it was shown that in FDM technology, in which PVA, PLA, and PVA/polyethylene glycol were used as polymers, obtained tablets also showed Korsmeyer Peppas kinetics [59]. Mechanism of ATH release from the 3D DLP obtained tablets was best fitted with the Korsmeyer-Peppas model, and increasing of ATH content did not influence drug release kinetics (Table 7).

Table 7. ATH drug release kinetics.

\begin{tabular}{cccc}
\hline Formulation & Model & $\mathbf{R}^{\mathbf{2}}$ Adjusted & $\boldsymbol{n}$ Value \\
\hline A1 & Korsmeyer-Peppas & 0.9893 & 0.413 \\
A2 & Korsmeyer-Peppas & 0.9854 & 0.437 \\
A3 & Korsmeyer-Peppas & 0.9787 & 0.395 \\
A4 & Korsmeyer-Peppas & 0.9944 & 0.388 \\
\hline
\end{tabular}

All formulations had release exponent $(n)$ below 0.45 , which indicates that ATH was released from tablets dominantly by following the Fickian diffusion mechanism [60]. It was expected that the change in the content of active substance did not affect the release kinetics, only the dissolution rate.

\section{Conclusions}

The possibility of successful 3D DLP printing, using the active substance suspended in the photopolymer mixture, for printing tablets in therapeutic doses for personalized therapy has been demonstrated. The highest content of the active substance (up to 25\%) using DLP technology has been incorporated in tablets so far, with flow properties and viscosity values of photoreactive suspensions suitable for 3D printing. Tablets with a higher amount of suspended ATH had shown an increased drug release rate after $8 \mathrm{~h}$, with increasing tensile strength, mass, and dimensions. All formulations showed Korsmeyer-Peppas kinetics after data fitting. Polarized light microscopy confirmed the presence of ATH crystals both in photoreactive suspensions and in the cross-sections of the tablets, while FT-IR analysis showed that there were no interactions between the active substance and other matrix components. All the obtained results indicated the expansion of the possibility of applying 3D printing techniques based on photopolymerization for pharmaceutical purposes. The application of this type of additive manufacturing provides an opportunity for quick and easy personalization of therapy, and all research with the presented advantages and disadvantages of DLP printing can indicate the direction of further development for potential application in pharmacy.

Author Contributions: Conceptualization, M.K., D.M., N.P., D.V., B.I., and S.I.; methodology, M.K., D.M., N.P., D.V., B.I., and S.I.; software, M.K.; validation, M.K., and D.M.; formal analysis: M.K., D.M., N.P., and B.I.; investigation, M.K.; resources, S.I.; data curation, M.K.; writing—original draft preparation, M.K.; writing—review and editing, M.K., D.M., N.P., D.V., and S.I.; visualization M.K., D.M., and S.I.; supervision D.M., D.V. and S.I.; project administration, S.I. All authors have read and agreed to the published version of the manuscript. 
Funding: This research was funded by the Ministry of Education Science and Technological Development, Republic of Serbia (451-03-68/2020-14/200161).

Conflicts of Interest: The authors declare no conflict of interest.

\section{References}

1. Alomari, M.; Mohamed, F.H.; Basit, A.W.; Gaisford, S. Personalised dosing: Printing a dose of one's own medicine. Int. J. Pharm. 2015, 494, 568-577. [CrossRef] [PubMed]

2. Azad, M.A.; Olawuni, D.; Kimbell, G.; Badruddoza, A.Z.M.; Hossain, M.S.; Sultana, T. Polymers for extrusion-based 3D printing of pharmaceuticals: A holistic materials-process perspective. Pharmaceutics 2020, 12, 124. [CrossRef] [PubMed]

3. Trenfield, S.J.; Awad, A.; Goyanes, A.; Gaisford, S.; Basit, A.W. 3D printing pharmaceuticals: Drug development to frontline care. Trends Pharmacol. Sci. 2018, 39, 440-451. [CrossRef] [PubMed]

4. Ngo, T.D.; Kashani, A.; Imbalzano, G.; Nguyen, K.T.Q.; Hui, D. Additive manufacturing (3D printing): A review of materials, methods, applications and challenges. Compos. Part B Eng. 2018, 143, 172-196. [CrossRef]

5. Goyanes, A.; Buanz, A.B.M.; Basit, A.W.; Gaisford, S. Fused-filament 3D printing (3DP) for fabrication of tablets. Int. J. Pharm. 2014, 476, 88-92. [CrossRef]

6. Khaled, S.A.; Burley, J.C.; Alexander, M.R.; Yang, J.; Roberts, C.J. 3D printing of five-in-one dose combination polypill with defined immediate and sustained release profiles. J. Control Release 2015, 217, 308-314. [CrossRef]

7. Khaled, S.A.; Burley, J.C.; Alexander, M.R.; Yang, J.; Roberts, C.J. 3D printing of tablets containing multiple drugs with defined release profiles. Int. J. Pharm. 2015, 494, 643-650. [CrossRef]

8. Okwuosa, T.C.; Stefaniak, D.; Arafat, B.; Isreb, A.; Wan, K.W.; Alhnan, M.A. A lower temperature FDM 3D printing for the manufacture of patient-specific immediate release tablets. Pharm. Res. 2016, 33, 2704-2712. [CrossRef]

9. Sadia, M.; Sośnicka, A.; Arafat, B.; Isreb, A.; Ahmed, W.; Kelarakis, A.; Alhnan, M.A. Adaptation of pharmaceutical excipients to FDM 3D printing for the fabrication of patient-tailored immediate release tablets. Int. J. Pharm. 2016, 513, 659-668. [CrossRef]

10. Khaled, S.A.; Alexander, M.R.; Wildman, R.D.; Wallace, M.J.; Sharpe, S.; Yoo, J.; Roberts, C.J. 3D extrusion printing of high drug loading immediate release paracetamol tablets. Int. J. Pharm. 2018, 538, 223-230. [CrossRef]

11. Wang, J.; Goyanes, A.; Gaisford, S.; Basit, A.W. Stereolithographic (SLA) 3D printing of oral modified-release dosage forms. Int. J. Pharm. 2016, 503, 207-212. [CrossRef] [PubMed]

12. Kadry, H.; Wadnap, S.; Xu, C.; Ahsan, F. Digital light processing (DLP) 3D-printing technology and photoreactive polymers in fabrication of modified-release tablets. Eur. J. Pharm. Sci. 2019, 135, 60-67. [CrossRef] [PubMed]

13. Melocchi, A.; Parietti, F.; Loreti, G.; Maroni, A.; Gazzaniga, A.; Zema, L. 3D printing by fused deposition modeling (FDM) of a swellable/erodible capsular device for oral pulsatile release of drugs. J. Drug Deliv. Sci. Technol. 2015, 30, 360-367. [CrossRef]

14. Solanki, N.G.; Tahsin, M.; Shah, A.V.; Serajuddin, A.T.M. Formulation of 3D printed tablet for rapid drug release by fused deposition modeling: Screening polymers for drug release, drug-polymer miscibility and printability. J. Pharm. Sci. 2018, 107, 390-401. [CrossRef] [PubMed]

15. Robles-Martinez, P.; Xu, X.; Trenfield, S.J.; Awad, A.; Goyanes, A.; Telford, R.; Basit, A.W.; Gaisford, S. 3D printing of a multi-layered polypill containing six drugs using a novel stereolithographic method. Pharmaceutics 2019, 11, 274. [CrossRef]

16. Krkobabić, M.; Medarević, D.; Cvijić, S.; Grujić, B.; Ibrić, S. Hydrophilic excipients in digital light processing (DLP) printing of sustained release tablets: Impact on internal structure and drug dissolution rate. Int. J. Pharm. 2019, 572, 118790. [CrossRef]

17. Katstra, W.E.; Palazzolo, R.D.; Rowe, C.W.; Giritlioglu, B.; Teung, P.; Cima, M.J. Oral dosage forms fabricated by Three Dimensional Printing(TM). J. Control Release 2000, 66, 1-9. [CrossRef]

18. Fina, F.; Goyanes, A.; Gaisford, S.; Basit, A.W. Selective laser sintering (SLS) 3D printing of medicines. Int. J. Pharm. 2017, 529, 285-293. [CrossRef] 
19. Trenfield, S.J.; Tan, H.X.; Goyanes, A.; Wilsdon, D.; Rowland, M.; Gaisford, S.; Basit, A.W. Non-destructive dose verification of two drugs within 3D printed polyprintlets. Int. J. Pharm. 2020, 577, 119066. [CrossRef]

20. Madla, C.M.; Trenfield, S.J.; Goyanes, A.; Gaisford, S.; Basit, A.W. 3D printing technologies, implementation and regulation: An overview. In 3D Printing of Pharmaceuticals; AAPS Advances in the Pharmaceutical Sciences Series; Basit, A.W., Gaisford, S., Eds.; Springer: Cham, Switzerland, 2018; Volume 31, pp. 21-40. [CrossRef]

21. Gibson, I.; Rosen, D.; Stucker, D. Additive Manufacturing Technologies, 2nd ed.; Springer: New York, NY, USA, 2015; pp. 63-103. [CrossRef]

22. Schmidt, J.; Colombo, P. Digital light processing of ceramic components from polysiloxanes. J. Eur. Ceram. Soc. 2018, 38, 57-66. [CrossRef]

23. Patel, D.K.; Sakhaei, A.H.; Layani, M.; Zhang, B.; Ge, Q.; Magdassi, S. Highly Stretchable and UV Curable Elastomers for Digital Light Processing Based 3D Printing. Adv. Mater. 2017, 29, 1-7. [CrossRef]

24. Choong, Y.Y.C.; Maleksaeedi, S.; Eng, H.; Su, P.C.; Wei, J. Curing characteristics of shape memory polymers in 3D projection and laser stereolithography. Virtual Phys. Prototyp. 2017, 12,77-84. [CrossRef]

25. Varghese, G.; Moral, M.; Castro-García, M.; López-López, J.J.; Marín-Rueda, J.R.; Yagüe-Alcaraz, V.; Hernández-Afonso, L.; Ruiz-Morales, J.C.; Canales-Vázquez, J. Fabrication and characterisation of ceramics via low-cost DLP 3D printing. Bol. La Soc. Esp. Ceram. Y Vidr. 2018, 57, 9-18. [CrossRef]

26. Kim, S.Y.; Shin, Y.S.; Jung, H.D.; Hwang, C.J.; Baik, H.S.; Cha, J.Y. Precision and trueness of dental models manufactured with different 3-dimensional printing techniques. Am. J. Orthod. Dentofac. Orthop. 2018, 153, 144-153. [CrossRef]

27. Yang, Y.; Zhou, Y.; Lin, X.; Yang, Q.; Yang, G. Printability of external and internal structures based on digital light processing 3D printing technique. Pharmaceutics 2020, 12, 207. [CrossRef] [PubMed]

28. Robles Martinez, P.; Basit, A.W.; Gaisford, S. The history, developments and opportunities of stereolithography. In $3 D$ Printing of Pharmaceuticals; AAPS Advances in the Pharmaceutical Sciences Series; Basit, A.W., Gaisford, S., Eds.; Springer: Cham, Switzerland, 2018; Volume 31, pp. 55-79. [CrossRef]

29. Yasmin, M.; Gupta, M.; Shukla, J.P. Molecular interactions and structural effects on mixing pentanol in polyethylene glycol diacrylate and polyethylene glycol dimethacrylate. J. Mol. Liq. 2011, 164, 212-217. [CrossRef]

30. Martinez, P.R.; Goyanes, A.; Basit, A.W.; Gaisford, S. Influence of geometry on the drug release profiles of stereolithographic (SLA) 3D-printed tablets. AAPS Pharm. Sci. Tech. 2018, 19, 3355-3361. [CrossRef]

31. Griffith, M.L.; Halloran, J.W. Freeform fabrication of ceramics via stereolithography. J. Am. Ceram. Soc. 1996, 79, 2601-2608. [CrossRef]

32. Wozniak, M.; Graule, T.; Hazan, Y.d.; Kata, D.; Lis, J. Highly loaded UV curable nanosilica dispersions for rapid prototyping applications. J. Eur. Ceram. Soc. 2009, 29, 2259-2265. [CrossRef]

33. Sweetman, S.C. Martindale, 36th ed.; Pharmaceutical Press: London, UK, 2009; p. 2151.

34. Bhitre, M.J.; Bhanage, B.; Shirgaonkar, S.J.; Pawar, A.S. Formulation and evaluation of elementary osmotic pump tablet of atomoxetine hydrochloride. Int. J. Pharm. Bio. Sci. 2013, 3, 118-134.

35. Madzarevic, M.; Medarevic, D.; Vulovic, A.; Sustersic, T.; Djuris, J.; Filipovic, N.; Ibric, S. Optimization and prediction of ibuprofen release from 3D DLP printlets using artificial neural networks. Pharmaceutics 2019, 11, 544. [CrossRef] [PubMed]

36. Fell, J.T.; Newton, J.M. Determination of tablet strength by the diametral-compression test. J. Pharm. Sci. 1970, 59, 688-691. [CrossRef]

37. Costa, P.; Sousa Lobo, J.M. Modeling and comparison of dissolution profiles. Eur. J. Pharm. Sci. 2001, 13, 123-133. [CrossRef]

38. Zhang, Y.; Huo, M.; Zhou, J.; Zou, A.; Li, W.; Yao, C.; Xie, S. DDSolver: An add-in program for modeling and comparison of drug dissolution profiles. AAPS J. 2010, 12, 263-271. [CrossRef] [PubMed]

39. ChemBK. Available online: https://www.chembk.com/en/chem/Atomoxetine (accessed on 21 August 2020).

40. Chartier, T.; Chaput, C.; Doreau, F.; Loiseau, M. Stereolithography of structural complex ceramic parts. J. Mater. Sci. 2002, 37, 3141-3147. [CrossRef]

41. Mezger, T.G. Applied Rheology, 1st ed.; Anton Paar GmbH: Graz, Austria, 2015.

42. Konijn, B.J.; Sanderink, O.B.J.; Kruyt, N.P. Experimental study of the viscosity of suspensions: Effect of solid fraction, particle size and suspending liquid. Powder Technol. 2014, 266, 61-69. [CrossRef] 
43. Luo, Y.; Le Fer, G.; Dean, D.; Becker, M.L. 3D printing of poly (propylene fumarate) oligomers: Evaluation of resin viscosity, printing characteristics and mechanical properties. Biomacromolecules 2019, 20, 1699-1708. [CrossRef]

44. Sauer, J.; Ring, B.J.; Witcher, J.W. Clinical pharmacokinetics of atomoxetine. Clin. Pharmacokinet. 2005, 44, 571-590. [CrossRef]

45. Zhang, Y.; Shen, L.; Wang, T.; Li, H.; Huang, R.; Zhang, Z.; Wang, Y.; Quan, D. Taste masking of water-soluble drug by solid lipid microspheres: A child-friendly system established by reversed lipid-based nanoparticle technique. J. Pharm. Pharmacol. 2020, 72, 776-786. [CrossRef]

46. Nutan, M.T.H.; Reddy, I.K. General principles of suspension. In Pharmaceutical Suspensions: For Formulations Development to Manufacturing; Kulshreshtha, A.K., Singh, O.N., Wall, G.M., Eds.; Springer: New York, NY, USA, 2010; pp. 39-65. [CrossRef]

47. Martinez, P.R.; Goyanes, A.; Basit, A.W.; Gaisford, S. Fabrication of drug-loaded hydrogels with stereolithographic 3D printing. Int. J. Pharm. 2017, 532, 313-317. [CrossRef]

48. Xu, X.; Robles-Martinez, P.; Madla, C.M.; Joubert, F.; Goyanes, A.; Basit, A.W.; Gaisford, S. Stereolithography (SLA) 3D printing of an antihypertensive polyprintlet: Case study of an unexpected photopolymer-drug reaction. Addit. Manuf. 2020, 33, 101071. [CrossRef]

49. Fernández-García, R.; Prada, M.; Bolás-Fernández, F.; Ballesteros, M.P.; Serrano, D.R. Oral fixed-dose combination pharmaceutical products: Industrial manufacturing versus personalized 3D printing. Pharm. Res. 2020, 37, 132. [CrossRef] [PubMed]

50. Huber, E.; Frost, M. Light scattering by small particles. J. Water Supply Res. Technol. AQUA 1998, 47, 87-94. [CrossRef]

51. Mitteramskogler, G.; Gmeiner, R.; Felzmann, R.; Gruber, S.; Hofstetter, C.; Stampfl, J.; Ebert, J.; Wachter, W.; Laubersheimer, J. Light curing strategies for lithography-based additive manufacturing of customized ceramics. Addit. Manuf. 2014, 1, 110-118. [CrossRef]

52. Spomer, N.; Klingmann, V.; Stoltenberg, I.; Lerch, C.; Meissner, T.; Breitkreutz, J. Acceptance of uncoated mini-tablets in young children: Results from a prospective exploratory cross-over study. Arch. Dis. Child. 2012, 97, 283-286. [CrossRef]

53. Pitt, K.G.; Webber, R.J.; Hill, K.A.; Dey, D.; Gamlen, M.J. Compression prediction accuracy from small scale compaction studies to production presses. Powder Technol. 2015, 270, 490-493. [CrossRef]

54. Clark, E.A.; Alexander, M.R.; Irvine, D.J.; Roberts, C.J.; Wallace, M.J.; Sharpe, S.; Yoo, J.; Hague, R.J.M.; Tuck, C.J.; Wildman, R.D. 3D printing of tablets using inkjet with UV photoinitiation. Int. J. Pharm. 2017, 529, 523-530. [CrossRef]

55. Pelras, T.; Glass, S.; Scherzer, T.; Elsner, C.; Schulze, A.; Abel, B. Transparent low molecular weight poly (ethylene glycol) diacrylate-based hydrogels as film media for photoswitchable drugs. Polymers 2017, 9, 693. [CrossRef]

56. Peter, M.; Tayalia, P. An alternative technique for patterning cells on poly (ethylene glycol) diacrylate hydrogels. RSC Adv. 2016, 6, 40878-40885. [CrossRef]

57. Banerjee, A.; Blasiak, B.; Pasquier, E.; Tomanek, B.; Trudel, S. Synthesis, characterization, and evaluation of PEGylated first-row transition metal ferrite nanoparticles as T2 contrast agents for high-field MRI. RSC Adv. 2017, 7, 38125-38134. [CrossRef]

58. Lakshmi, P.; Harini, K. Design and Optimization of thermo-reversible nasal in situ gel of atomoxetine hydrochloride using taguchi orthogonal array design. Dhaka Univ. J. Pharm. Sci. 2019, 18, 183-193. [CrossRef]

59. Cerda, J.R.; Arifi, T.; Ayyoubi, S.; Knief, P.; Paloma Ballesteros, M.; Keeble, W.; Barbu, E.; Marie Healy, A.; Lalatsa, A.; Serrano, D.R. Personalised 3D printed medicines: Optimising material properties for successful passive diffusion loading of filaments for fused deposition modelling of solid dosage forms. Pharmaceutics 2020, 12, 345. [CrossRef] [PubMed]

60. Razzak, M.S.M.I.; Khan, F.; Khan, M.Z.R.; Fatema, K.; Islam, M.S.; Reza, M.S. Effect of channeling agents on the release profile of theophylline from METHOCEL K4M based matrix tablets. Dhaka Univ. J. Pharm. Sci. 2008, 7, 27-32. [CrossRef]

(C) 2020 by the authors. Licensee MDPI, Basel, Switzerland. This article is an open access article distributed under the terms and conditions of the Creative Commons Attribution (CC BY) license (http://creativecommons.org/licenses/by/4.0/). 